\title{
Investigation of Biogas Potential of Plantain Peels Mixed with Poultry Droppings as an Alternative Energy Source and Its Statistical Analysis
}

\author{
Adepoju $\mathrm{PO}^{1}$, Adeniran $\mathrm{KA}^{1}$ and Adepoju $\mathrm{TF}^{2 *}$ \\ ${ }^{1}$ Agricultural and Biosystems Engineering Department, Faculty of Engineering, Kwara State, Nigeria \\ ${ }^{2}$ Chemical/Petrochemical Engineering Department, Ikot Akpaden, Nigeria
}

*Corresponding author: Adepoju TF, Chemical/Petrochemical Engineering Department, Nigeria

\section{ARTICLE INFO}

Received: 慧 April 24, 2020

Published: 慧 May 04, 2020

Citation: Adepoju PO, Adeniran KA, Adepoju TF. Investigation of Biogas Potential of Plantain Peels Mixed with Poultry Droppings as an Alternative Energy Source and Its Statistical Analysis. Biomed J Sci \& Tech Res 27(3)-2020. BJSTR. MS.ID.004497.

Keywords: Plantain peels; Poultry Droppings; Biogas; Optimization; Chemical and Proximate Composition

\begin{abstract}
Biogas offers a clean, cheap, non-toxic with characteristics of renewability, sustainability, and environmentally friendly source of energy when compared to fossil fuel. Plantain peel is a kitchen waste which is an organic material with high calorific and nutritive values with efficiency for methane production. On the other hand, poultry droppings are solid waste with a higher proportion of biodegradable organic matter than the excrement of any other livestock. An alternative way of managing both the kitchen and solid wastes is anaerobic digestion, which transforms organic materials under oxygen-free conditions into biogas. In this study, anaerobic digestion of plantain peels and poultry droppings was investigated using a batch reactor plant of $250 \mathrm{~L}$ capacities, with a retention time of 50 days and its statistical analysis using a fourfactor response surface methodology (RSM). Chemical and proximate compositions of digestate were carried out and their potential use for agricultural purposes. Result obtained from poultry droppings with plantain peels indicates the maximum biogas yield as $3.06 \times 10^{-2} \mathrm{~m}^{3} /$ day. Analysis of variance of regression equation shows the coefficient of determination $\left(\mathrm{R}^{2}\right)$ of $99.67 \%$. Four different temperatures (ambient, slurry, gas layer, and the interface between slurry and gas layer) were measured during the energy recovery process and were found to be within the mesophilic temperature range. These results demonstrate that poultry droppings mixed with plantain peels are a readily digestible substrate with excellent potential for biogas production and agricultural purposes.
\end{abstract}

\section{Introduction}

Biogas as an alternative source of energy is being recognized globally as of recent [1]. According to the International Energy Association (IEA), the anaerobic digesters for producing biogas using waste materials are over 9000. The process of generating energy from wastes gives the benefit of environmental protection and energy recovery. The potential feedstock for biogas production includes; municipal solid waste, industrial organic waste, garden waste, agricultural waste, energy crops, cellulose-rich biomass, algae, and seaweed, a by-product of ethanol and biodiesel production [2]. Poultry droppings or liter is a mixture of bedding materials such as sawdust, woodchips, rice hulls, etc. and animal excreta. The nutrient content of litters differs from households and within the same house condition on location and management [3], the physical structures of poultry droppings on the average are feces, urine, and litters which made up the nitrates. Plantain peels which are kitchen wastes are disposed of in landfill which causes public health hazards and diseases such as cholera, typhoid, etc. because of inadequate management of wastes like uncontrolled dumping which bears several adverse consequences such as pollution of surface and groundwater through leachate and breeding of flies, mosquitoes, rat and other disease-bearing vectors with unpleasant odor and methane which is a major greenhouse gas contributing to global warming [4].

Anaerobic digestion is a process of treating and converting wastes to biogas, its benefits include organic loading in a small reactor plant, lower emission of air, and a minimal amount of generated sludge in comparison with aerobic biological treatment $[5,6]$. Food waste mixed with animal manure has been investigated 
in earlier reported anaerobic digestion studies for biogas production [7-10], and poultry droppings, cow dung, and kitchen wastes [9], the average biogas production according to [9] show that poultry droppings gave the highest biogas yield. The objective of this study is to employ a small scale anaerobic digestion system to assess the methane yield and treatment efficiency of poultry droppings and plantain peels. Statistical analysis and optimization using a fourfactor response surface methodology were carried out to estimate the biogas production. The thermal treatment of substrates was also carried out as an effort to remove adherent dirt and to minimize water use in the feed. The effects of process parameters including substrate composition, hydraulic retention time, and operational changes on the system performance are reported.

\section{Material and Method}

\section{Materials}

The anaerobic digestion system employed in this study comprises of gas holder, anaerobic digester, a water displacement tank, and a vulgarizer tube for biogas storage. The digester has a 250L capacity and a cylindrical shape with a conical bottom for the slurry outlet. Poultry droppings were obtained from Hadebs farm Kilanko Offa garage Ilorin, while plantain peels were collected from a restaurant (item 7) within the University of Ilorin, Kwara State Nigeria. $\mathrm{pH}$ meter was used in monitoring the $\mathrm{pH}$ of the slurry. The reagents used were of analytical grades with no further purification and includes distilled water, sodium hydroxide, ferric chloride, and activated carbon pellets. Temperature sensors, amplifiers, and data loggers were used to monitor the temperatures (slurry, gas layer, ambient, and the interface between slurry and gas layer). The temperature sensors were connected to the amplifier to amplify the signal from the sensors and for easy detection on the data logger

\section{Evaluation Procedure}

The evaluation period lasted for 50 days. The evaluation was divided into three intensive evaluation periods. The first stage was the preparation, design, and loading of substrates, the second evaluation was the steady stage of relatively consistent biogas production and intensive measurement, desulphurization, and data collection while the final stage is the data analysis whereby the data collected were optimized.

During the first stage of preparation, design, and loading; the 250L capacity digester was fabricated from galvanized steel by the method used by [11]. The digester was airtight, painted black with heights above ground level for exposure to sunlight penetration. Poultry droppings mixed with plantain peels were thermally treated at $50^{\circ} \mathrm{C}$ and mixed with distilled water in a reactor mix bucket to reduce the viscosity of the digestate and to remove adherent dirt. Plantain peels were milled to reduce the particle size, washed with distilled water before mixing with poultry droppings. The $\mathrm{pH}$ of the slurry after mixing was 5.4, therefore few droplets of $\mathrm{NaOH}(\mathrm{aq})$ was added to the slurry to reduce the acidity to 7.21 for organism adaptation during anaerobic digestion. The digester occupied 2/3rd of the digester space leaving a height of $29.1 \mathrm{~cm}$ for gas production. In order for solid accumulation at the bottom and for easy removal after digestion, the slurry inflow was directed downward, the content of the digester was manually stirred for uniformity of microbial activity in the digester daily at 9 am, $1 \mathrm{pm}$ and $5 \mathrm{pm}$ respectively. The ratio of feed was $1 \mathrm{~kg}$ of poultry droppings, $2 \mathrm{~kg}$ of distilled water, and $1 \mathrm{~kg}$ of plantain peels.

The second evaluation which is the steady stage of relatively consistent biogas production and intensive measurement, desulphurization, and data collection, the gas was collected by water displacement method, temperatures were monitored and the $\mathrm{pH}$ of the slurry and height of biogas holder was measured daily. Raw biogas was allowed to pass through the desulphurization chamber which contains activated carbon pellets and ferric chloride to remove $\mathrm{CO}_{2}$ and $\mathrm{H}_{2} \mathrm{~S}$ from the biogas. Data on the height of digester displaced and $\mathrm{pH}$ were measured daily and temperatures were recorded on a data logger. The final stage of data analysis was carried out using Microsoft Excel with Linear Regression and Correlation to evaluate the regression parameters $\beta$ o (intercept) and $\beta 1$ (slope) too respectively with the equation below

$$
\begin{gathered}
\beta 0=(Y i-\beta 1 X i) \\
\beta 1=\frac{S x y}{S x x}
\end{gathered}
$$

Where $S x y=\sum\left(X_{i}-\bar{X}\right)\left(Y_{i}-\bar{Y}\right)$

$$
S x x=\sum\left(X_{i}-\bar{X}\right)
$$

$\bar{Y}=$ average mean of biogas volume

$\bar{X}$ =average mean of number of days

In the optimization design of biogas production, Central Composite Optimal Design (CCOD) was employed to correlate the relationship between the biogas produced and temperatures. Fivelevel-four-factor design was applied, the central point was increased by 2 step-lengths, and the central point per group was increased by a step length while the run per HTC axial group was also increased by 2 step length. Chosen alpha spherical 2 with $\mathrm{K}>5=1.41421$ with face-centered 1, 50 experimental runs were generated. This included 16 factorial points, 14 axial points, and 20 central points to provide information regarding the interior of the experimental region, making it possible to evaluate the curvature effect. Selected factors for biogas production were ambient temperature $\left(\mathrm{T}_{\mathrm{amb}}\right)$, slurry temperature $\left(\mathrm{T}_{\text {slurry }}\right)$, interface temperature $\left(\mathrm{T}_{\text {int }}\right)$, and gas layer temperature $\left(\mathrm{T}_{\mathrm{Glt}}\right)$ (Table 1$)$. The quality of the fit of the model was evaluated using the test of significance and analysis of variance (ANOVA). The fitted quadratic response model is described by Eq. (3).

$$
Y=b_{0}+\sum_{i=1}^{k} b_{i} X_{i}+\sum_{i=1}^{k} b_{i i} X_{i}^{2}+\sum_{i=1}^{k} b_{i j} X_{i} X_{j}+e
$$


Table 1: Factors and their Levels for Composite Central Design.

\begin{tabular}{|c|c|c|c|c|c|c|c|}
\hline Variable & Abbreviation & Symbol & \multicolumn{4}{|c|}{ Coded factor levels } \\
\hline & & & -2 & -1 & 0 & 1 & 2 \\
\hline Ambient temperature $\left({ }^{\circ} \mathrm{C}\right)$ & $\mathrm{T}_{\text {amb }}$ & $\mathrm{X}_{1}$ & 23 & 25 & 27 & 29 & 31 \\
\hline Slurry temperature $\left({ }^{\circ} \mathrm{C}\right)$ & $\mathrm{T}_{\text {slury }}$ & $\mathrm{X}_{2}$ & 13 & 19 & 25 & 31 & 37 \\
\hline Interface temperature $\left({ }^{\circ} \mathrm{C}\right)$ & $\mathrm{T}_{\text {int }}$ & $\mathrm{X}_{3}$ & 26 & 28 & 30 & 32 & 35 \\
\hline Gas layer temperature $\left({ }^{\circ} \mathrm{C}\right)$ & $\mathrm{G}_{\text {lt }}$ & $\mathrm{X}_{4}$ & 23 & 26 & 29 & 32 & 34 \\
\hline
\end{tabular}

\section{Where:}

$\mathrm{Y}$ is response factor (biogas volume), $\mathrm{b}_{\mathrm{o}}$ is the intercept value, $b_{i}(i=1,2, k)$ is the first order model coefficient, $b_{i j}$ is the interaction effect, and $b_{i j}$ represents the quadratic coefficients of $\mathrm{Xi}$, and $\mathrm{e}$ is the random error.

\section{Chemical and Proximate Analyses of the Digestates}

Chemical and proximate compositional analysis of the digestate such as ash content, carbon content, nitrogen content, calcium, $\mathrm{pH}$, phosphorus, potassium, and $\mathrm{C} / \mathrm{N}$ ratio were carried out using the method already adopted by [11].

\section{Results and Discussion}

\section{Biogas Yield}

The biogas yield contains methane $\left(\mathrm{CH}_{4}\right)$, with a major gas of carbon dioxide $\left(\mathrm{CO}_{2}\right)$ and trace gas such as hydrogen sulfide $\left(\mathrm{H}_{2} \mathrm{~S}\right)$. From the beginning of the digestion process, biogas yield was slow till it reached a maximum volume of $3.06 \times 10^{-2} \mathrm{~m}^{3} /$ day on the $18^{\text {th }}$ day of the production process and then continued to vary till the $50^{\text {th }}$ day of the fermentation process when the biogas yield maintained a steady volume. The volume of biogas was calculated by multiplying the cross-sectional area with the height of digester displaced throughout the fermentation process. According to [10] who produced biogas from poultry droppings found out that it produced more biogas because it contains more nutrients and nitrogen in comparison with other animal waste except for pig waste, but it also produces a small proportion of $\mathrm{H}_{2} \mathrm{~S}$ which corrodes metal fitting. Table 1 presents the daily biogas readings, cross-sectional area, and height of digester for 50 days of the fermentation period.

\section{Relationship between Temperature and pH}

The $\mathrm{pH}$ during the fermentation process is vital to methane production because it influences the reaction of the microbial life growth during anaerobic digestion. Anaerobes prefer a $\mathrm{pH}$ close to neutral in the range of $6.8-7.2$ [12]. Throughout the period of fermentation, the $\mathrm{pH}$ was between 7.21 to 5.24 which are within the generally accepted optimum methane fermentation $\mathrm{pH}$ range of approximately 6.5 to 8.2 [13]. There are three temperature ranges selected for different bacteria; the psychrophilic range $<<$ $30^{\circ} \mathrm{C}$ ), mesophilic range (between $30-40^{\circ} \mathrm{C}$ ), and the thermophilic range $\left(50-60^{\circ} \mathrm{C}\right)$ [11]. Table 2 shows the retention time and daily temperatures recorded of the morning ( $9 \mathrm{am})$, afternoon (1 pm) and evening ( $5 \mathrm{pm}$ ) for the four different layers (ambient, slurry, interface between slurry and gas and gas layer). The temperatures during the fermentation process were found to be within the mesophilic temperature range $\left(30-40^{\circ} \mathrm{C}\right)$ which is attributed to the weather conditions of the area of experiment. It was noted that daily gas generation does not follow a specific pattern and it can be concluded that other parameters apart from temperature and $\mathrm{pH}$ could have been responsible for the amount of biogas produced daily. From the earlier reported work on biogas production, it was said that the retention time, substrates, composition of feedstock greatly affect the rate of biogas production [11].

Table 2: Biogas yield, cross sectional area and height of digester displaced.

\begin{tabular}{|c|c|c|c|c|c|c|c|}
\hline Days & $\begin{array}{l}\text { Cross sectional } \\
\text { area }\left(\mathbf{m}^{2}\right)\end{array}$ & Height $\left(m^{2}\right)$ & $\begin{array}{l}\text { Biogas Volume } \\
\left(\mathrm{m}^{3}\right) \times 10^{-2}\end{array}$ & Days & $\begin{array}{l}\text { Cross sectional } \\
\text { area }\left(\mathrm{m}^{2}\right)\end{array}$ & Height $\left(m^{2}\right)$ & $\begin{array}{l}\text { Biogas Volume } \\
\qquad\left(\mathrm{m}^{3}\right) \times 10^{-2}\end{array}$ \\
\hline 1 & 1.07 & 1.94 & 2.07 & 26 & 1.07 & 2.17 & 2.31 \\
\hline 2 & 1.07 & 2.01 & 2.15 & 27 & 1.07 & 2.16 & 2.3 \\
\hline 3 & 1.07 & 2.03 & 2.17 & 28 & 1.07 & 2.17 & 2.31 \\
\hline 4 & 1.07 & 2.11 & 2.25 & 29 & 1.07 & 1.95 & 2.08 \\
\hline 5 & 1.07 & 2.14 & 2.28 & 30 & 1.07 & 1.95 & 2.08 \\
\hline 6 & 1.07 & 2.17 & 2.31 & 31 & 1.07 & 2.13 & 2.27 \\
\hline 7 & 1.07 & 2.02 & 2.16 & 32 & 1.07 & 2.17 & 2.31 \\
\hline 8 & 1.07 & 1.97 & 2.1 & 33 & 1.07 & 2.08 & 2.22 \\
\hline 9 & 1.07 & 2.02 & 2.16 & 34 & 1.07 & 2.21 & 2.36 \\
\hline 10 & 1.07 & 1.99 & 2.13 & 35 & 1.07 & 2.87 & 3.06 \\
\hline 11 & 1.07 & 2.17 & 2.31 & 36 & 1.07 & 2.81 & 3 \\
\hline 12 & 1.07 & 2.15 & 2.28 & 37 & 1.07 & 2.87 & 3.06 \\
\hline
\end{tabular}




\begin{tabular}{|c|c|c|c|c|c|c|c|}
\hline 13 & 1.07 & 2.21 & 2.36 & 38 & 1.07 & 2.77 & 2.96 \\
\hline 14 & 1.07 & 2.14 & 2.28 & 39 & 1.07 & 2.87 & 3.06 \\
\hline 15 & 1.07 & 2.16 & 2.3 & 40 & 1.07 & 2.80 & 2.99 \\
\hline 16 & 1.07 & 2.08 & 2.22 & 41 & 1.07 & 2.87 & 3.06 \\
\hline 17 & 1.07 & 2.86 & 3.05 & 42 & 1.07 & 2.87 & 3.06 \\
\hline 18 & 1.07 & 2.87 & 3.06 & 43 & 1.07 & 2.81 & 3 \\
\hline 19 & 1.07 & 2.86 & 3.05 & 44 & 1.07 & 2.87 & 3.06 \\
\hline 20 & 1.07 & 2.87 & 3.06 & 45 & 1.07 & 2.91 & 3.1 \\
\hline 21 & 1.07 & 2.05 & 2.19 & 46 & 1.07 & 2.87 & 3.06 \\
\hline 22 & 1.07 & 2.05 & 2.19 & 47 & 1.07 & 2.87 & 3.06 \\
\hline 23 & 1.07 & 2.04 & 2.18 & 48 & 1.07 & 2.92 & 3.11 \\
\hline 24 & 1.07 & 2.05 & 2.19 & 49 & 1.07 & 2.87 & 3.06 \\
\hline 25 & 1.07 & 2.17 & 2.31 & 50 & 1.07 & 2.87 & 3.06 \\
\hline
\end{tabular}

Statistical analysis by Response Surface Methodology (RSM)

Design Expert 12.0.3.1 software was employed to evaluate the coefficients of the full regression model equation and their statistical significance. A graph can provide a visual method to observe responsive value and to test parameter level relation. Figure 1(a-f) shows the contour and the 3-dimensional response surface plots representing the effect of ambient temperature $\left(\mathrm{T}_{\mathrm{amb}}\right)$, slurry temperature $\left(\mathrm{T}_{\text {slurry }}\right)$, interface temperature $\left(\mathrm{T}_{\text {int }}\right)$, and gas layer temperature $\left(\mathrm{T}_{\mathrm{Glt}}\right)$ on the volume of biogas produced. Results show that there were perfect interactions between the selected variables and the volume of biogas produced, it was noticed that the mutual effects between slurry with ambient temperatures, interface with slurry temperatures indicated superiority over other factors. Tables $3 \& 4$ shows the analysis of variance (ANOVA) of the regression equation. The results showed that the $p$-values of the model terms were significant, i.e. $p<0.05$. In this case, the two linear terms $\left(\mathrm{X}_{1}, \mathrm{X}_{4}\right)$, the four cross-products $\left(\mathrm{X}_{1} \mathrm{X}_{2}, \mathrm{X}_{1} \mathrm{X}_{3}, \mathrm{X}_{2} \mathrm{X}_{4}, \mathrm{X}_{3} \mathrm{X}_{4}\right.$ where the terms $X_{1}, X_{2}, X_{3}$, and $X_{4}$ ) and the four quadratic terms $\left(\mathrm{X}_{12}, \mathrm{X}_{22}, \mathrm{X}_{32}\right.$ and $\left.\mathrm{X}_{42}\right)$ were all remarkably significant model terms at $95 \%$ confidence level except $X_{2}, X_{3}, X_{2} X_{3}$, and $X_{1} X_{4}$. However, all other model terms were more significant than $\mathrm{X}_{2} \mathrm{X}_{4}$. In order to minimize error, all the coefficients were considered in the design. The coefficient of determination $\left(\mathrm{R}^{2}\right)$ was $99.67 \%$, R-Sq. (adj.) was found to be $99.51 \%$ and all p-value coefficients were less than 0.1 , which implied that the model proved suitable for the adequate representation of the actual relationship among the selected factors. These values revealed that this regression was statistically significant; only $0.033 \%$ of total variations were not explained by this regression model. Meanwhile, the $\mathrm{R}^{2}$ indicated a high consistency between the experimental values and the predicted values. The final equation was done in terms of actual factors for the central composite optimal design response surface quadratic model is expressed in Eq. (4).

$Y \times 10^{-2}\left(m^{3}\right)=-23.08531+0.658030 X_{1}+0.107524 X_{2}+0.618295 X_{3}+0.440287 X_{4}-0.000456 X_{1} X_{2}+0.001076 X_{1} X_{3}+0.000199 X_{1} X_{4}-0.000104 X_{2} X_{3}$

$-0.000275 X_{2} X_{4}-0.002399 X_{3} X_{4}-0.012542 X_{1}^{2}-0.001691 X_{2}^{2}-0.009429 X_{3}^{2}-0.006312 X_{2}^{2}$

Table 3: Retention time, and daily temperatures of the fermentation process.

\begin{tabular}{|c|c|c|c|c|c|c|c|c|c|c|c|c|c|}
\hline \multirow{2}{*}{ Date } & \multirow{2}{*}{ Days } & \multicolumn{4}{|c|}{ Morning } & \multicolumn{4}{|c|}{ Afternoon } & \multicolumn{4}{|c|}{ Evening } \\
\hline & & amb & slurry & interface & gas & amb & slurry & interface & gas & amb & slurry & interface & gas \\
\hline 02/07/19 & 1 & 25 & 23 & 24 & 26 & 23 & 29 & 34 & 26 & 29 & 28 & 32 & 34 \\
\hline 03/07/19 & 2 & 24 & 26 & 24 & 27 & 23 & 28 & 34 & 25 & 26 & 27 & 33 & 34 \\
\hline 04/07/19 & 3 & 26 & 27 & 26 & 24 & 24 & 36 & 34 & 35 & 27 & 26 & 33 & 33 \\
\hline 05/07/19 & 4 & 25 & 28 & 26 & 24 & 25 & 37 & 34 & 34 & 25 & 29 & 30 & 33 \\
\hline 06/07/19 & 5 & 24 & 29 & 26 & 24 & 26 & 25 & 32 & 34 & 26 & 18 & 30 & 34 \\
\hline $07 / 07 / 19$ & 6 & 26 & 21 & 26 & 24 & 30 & 36 & 32 & 34 & 27 & 18 & 31 & 32 \\
\hline 08/07/19 & 7 & 27 & 23 & 26 & 25 & 29 & 29 & 31 & 30 & 28 & 25 & 29 & 32 \\
\hline 09/07/19 & 8 & 24 & 25 & 26 & 24 & 27 & 28 & 34 & 29 & 26 & 25 & 34 & 33 \\
\hline $10 / 07 / 19$ & 9 & 29 & 27 & 29 & 28 & 25 & 27 & 34 & 26 & 27 & 28 & 29 & 32 \\
\hline $11 / 07 / 19$ & 10 & 26 & 28 & 29 & 26 & 27 & 20 & 35 & 33 & 28 & 24 & 33 & 31 \\
\hline $12 / 07 / 19$ & 11 & 25 & 25 & 29 & 29 & 30 & 27 & 27 & 30 & 27 & 19 & 32 & 30 \\
\hline $13 / 07 / 19$ & 12 & 28 & 26 & 28 & 27 & 28 & 28 & 26 & 30 & 28 & 25 & 32 & 30 \\
\hline $14 / 07 / 19$ & 13 & 26 & 21 & 25 & 32 & 30 & 24 & 26 & 28 & 27 & 27 & 34 & 31 \\
\hline
\end{tabular}




\begin{tabular}{|c|c|c|c|c|c|c|c|c|c|c|c|c|c|}
\hline $15 / 07 / 19$ & 14 & 28 & 22 & 32 & 30 & 30 & 26 & 27 & 28 & 26 & 26 & 25 & 32 \\
\hline $16 / 07 / 19$ & 15 & 25 & 23 & 24 & 32 & 27 & 23 & 27 & 30 & 27 & 29 & 26 & 28 \\
\hline $17 / 07 / 19$ & 16 & 24 & 21 & 24 & 24 & 28 & 25 & 28 & 23 & 26 & 28 & 33 & 28 \\
\hline $18 / 07 / 19$ & 17 & 20 & 22 & 24 & 26 & 30 & 23 & 26 & 30 & 27 & 18 & 32 & 29 \\
\hline $19 / 07 / 19$ & 18 & 22 & 23 & 22 & 30 & 28 & 22 & 26 & 30 & 26 & 16 & 34 & 34 \\
\hline $20 / 07 / 19$ & 19 & 20 & 29 & 26 & 29 & 29 & 31 & 30 & 30 & 27 & 18 & 32 & 28 \\
\hline $21 / 07 / 19$ & 20 & 22 & 28 & 25 & 30 & 30 & 30 & 28 & 30 & 28 & 23 & 31 & 29 \\
\hline $22 / 07 / 19$ & 21 & 22 & 30 & 24 & 36 & 29 & 22 & 27 & 30 & 26 & 24 & 32 & 30 \\
\hline $23 / 07 / 19$ & 22 & 21 & 23 & 31 & 28 & 30 & 21 & 28 & 28 & 27 & 25 & 29 & 30 \\
\hline $24 / 07 / 19$ & 23 & 25 & 24 & 23 & 33 & 30 & 20 & 35 & 24 & 29 & 16 & 29 & 34 \\
\hline $25 / 07 / 19$ & 24 & 29 & 22 & 28 & 29 & 30 & 22 & 33 & 30 & 29 & 27 & 33 & 30 \\
\hline $26 / 07 / 19$ & 25 & 23 & 23 & 26 & 28 & 30 & 16 & 35 & 28 & 28 & 28 & 34 & 31 \\
\hline $27 / 07 / 19$ & 26 & 24 & 25 & 24 & 32 & 30 & 15 & 27 & 30 & 26 & 29 & 32 & 28 \\
\hline $28 / 07 / 19$ & 27 & 23 & 26 & 26 & 28 & 30 & 13 & 33 & 34 & 27 & 26 & 28 & 34 \\
\hline $29 / 07 / 19$ & 28 & 24 & 28 & 26 & 31 & 30 & 16 & 32 & 32 & 27 & 27 & 32 & 32 \\
\hline $30 / 07 / 19$ & 29 & 24 & 28 & 26 & 29 & 30 & 20 & 32 & 33 & 28 & 27 & 27 & 30 \\
\hline $31 / 07 / 19$ & 30 & 25 & 23 & 25 & 32 & 31 & 16 & 32 & 30 & 26 & 18 & 27 & 29 \\
\hline $01 / 08 / 19$ & 31 & 26 & 25 & 26 & 27 & 32 & 17 & 31 & 32 & 25 & 19 & 26 & 27 \\
\hline 02/08/19 & 32 & 27 & 23 & 26 & 26 & 32 & 18 & 31 & 31 & 25 & 21 & 26 & 27 \\
\hline $03 / 08 / 19$ & 33 & 27 & 24 & 27 & 27 & 32 & 20 & 32 & 31 & 26 & 22 & 27 & 27 \\
\hline 04/08/19 & 34 & 29 & 23 & 27 & 28 & 33 & 23 & 31 & 29 & 26 & 23 & 29 & 28 \\
\hline 05/08/19 & 35 & 27 & 23 & 27 & 28 & 30 & 22 & 29 & 27 & 27 & 24 & 29 & 29 \\
\hline 06/08/19 & 36 & 28 & 25 & 29 & 29 & 31 & 24 & 30 & 27 & 29 & 26 & 31 & 30 \\
\hline 07/08/19 & 37 & 28 & 26 & 29 & 28 & 31 & 24 & 28 & 26 & 29 & 27 & 32 & 31 \\
\hline 08/08/19 & 38 & 29 & 26 & 27 & 29 & 29 & 24 & 28 & 29 & 29 & 29 & 33 & 31 \\
\hline 09/08/19 & 39 & 29 & 26 & 28 & 29 & 29 & 25 & 29 & 28 & 30 & 29 & 34 & 30 \\
\hline $10 / 08 / 19$ & 40 & 30 & 27 & 28 & 28 & 30 & 26 & 29 & 27 & 30 & 29 & 34 & 31 \\
\hline $11 / 08 / 19$ & 41 & 28 & 25 & 26 & 28 & 28 & 24 & 29 & 27 & 29 & 27 & 32 & 29 \\
\hline $12 / 08 / 19$ & 42 & 29 & 25 & 27 & 28 & 28 & 25 & 30 & 26 & 28 & 26 & 32 & 30 \\
\hline $13 / 08 / 19$ & 43 & 29 & 26 & 27 & 29 & 29 & 23 & 31 & 25 & 29 & 28 & 33 & 30 \\
\hline $14 / 08 / 19$ & 44 & 30 & 27 & 29 & 30 & 32 & 26 & 30 & 27 & 31 & 29 & 34 & 30 \\
\hline $15 / 08 / 19$ & 45 & 30 & 27 & 29 & 30 & 30 & 27 & 29 & 30 & 30 & 24 & 26 & 25 \\
\hline $16 / 08 / 19$ & 46 & 29 & 26 & 27 & 29 & 29 & 26 & 27 & 29 & 30 & 23 & 26 & 25 \\
\hline $17 / 08 / 19$ & 47 & 29 & 26 & 27 & 29 & 29 & 25 & 27 & 27 & 30 & 22 & 30 & 27 \\
\hline $18 / 08 / 19$ & 48 & 29 & 26 & 27 & 29 & 29 & 26 & 27 & 27 & 29 & 26 & 25 & 24 \\
\hline $19 / 08 / 19$ & 49 & 30 & 27 & 29 & 30 & 31 & 26 & 31 & 28 & 30 & 26 & 29 & 25 \\
\hline $20 / 08 / 19$ & 50 & 30 & 27 & 29 & 30 & 31 & 26 & 31 & 28 & 30 & 26 & 30 & 26 \\
\hline
\end{tabular}

Table 4: Analysis of Variance (ANOVA) of Regression Equation.

\begin{tabular}{|c|c|c|c|}
\hline Source & Coefficient Estimate & Standard Error & VIF \\
\hline Intercept & 3.05 & 0.0069 & \\
\hline Whole-plot Terms: & & & 0.0048 \\
\hline $\mathrm{X}_{1}$ & 0.0313 & 0.0032 & 1.0000 \\
\hline $\mathrm{X}_{1}{ }_{\text {Subplot Terms: }}$ & -0.2006 & & \\
\hline $\mathrm{X}_{2}$ & & 0.0056 & 1.0000 \\
\hline $\mathrm{X}_{3}$ & -0.0037 & 0.0056 & 1.0000 \\
\hline $\mathrm{X}_{4}$ & 0.0054 & 0.0056 & 1.0000 \\
\hline $\mathrm{X}_{1} \mathrm{X}_{2}$ & 0.0321 & 0.0069 & 1.0000 \\
\hline
\end{tabular}




\begin{tabular}{|c|c|c|c|}
\hline $\mathrm{X}_{1} \mathrm{X}_{3}$ & 0.0194 & 0.0069 & 1.0000 \\
\hline $\mathrm{X}_{1} \mathrm{X}_{4}$ & 0.0044 & 0.0069 & 1.0000 \\
\hline $\mathrm{X}_{2} \mathrm{X}_{3}$ & -0.0056 & 0.0069 & 1.0000 \\
\hline $\mathrm{X}_{2} \mathrm{X}_{4}$ & -0.0181 & 0.0069 & 1.0000 \\
\hline $\mathrm{X}_{3} \mathrm{X}_{4}$ & -0.0594 & 0.0069 & 1.0000 \\
\hline $\mathrm{X}_{2}^{2}$ & -0.2434 & 0.0049 & 1.01 \\
\hline $\mathrm{X}_{3}^{2}$ & -0.1909 & 0.0049 & 1.01 \\
\hline $\mathrm{X}_{4}^{2}$ & -0.1909 & 0.0049 & 1.01 \\
\hline Std. Dev. & 0.0284 & $\mathbf{R}^{2}$ & 0.9967 \\
\hline Mean & 2.56 & Adjusted $\mathrm{R}^{2}$ & 0.9951 \\
\hline C.V. \% & 1.11 & & \\
\hline
\end{tabular}

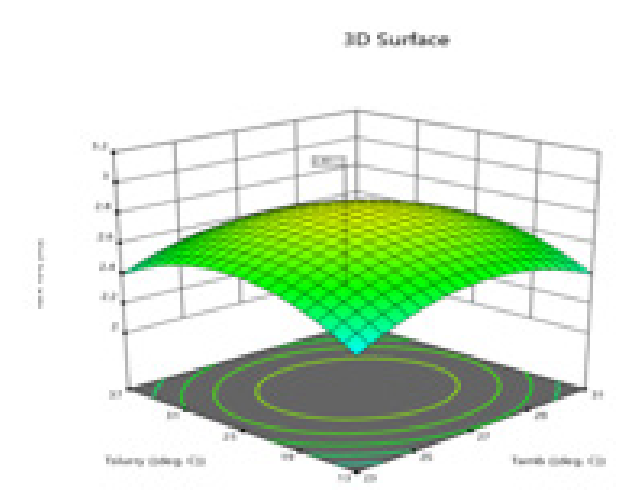

(a)

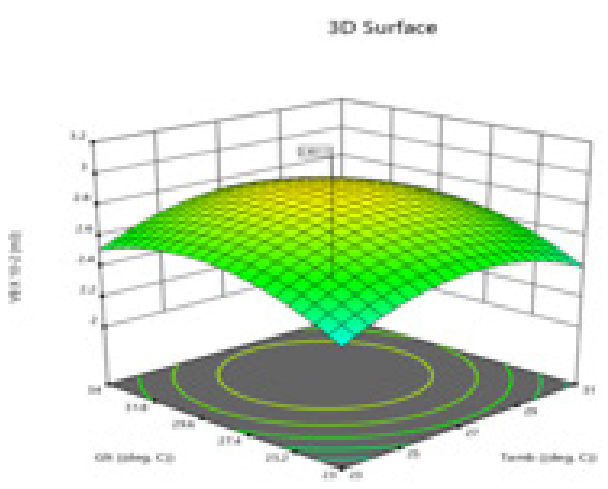

(c)

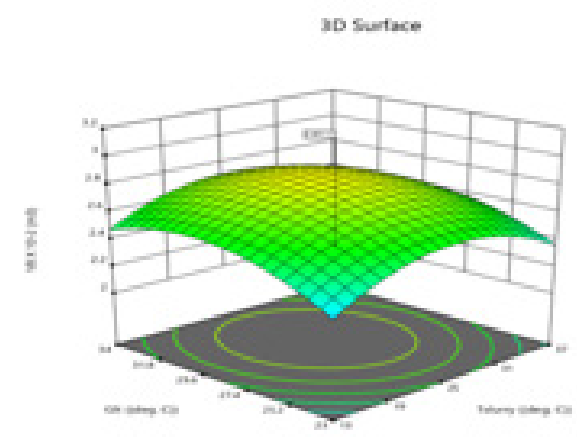

(e)

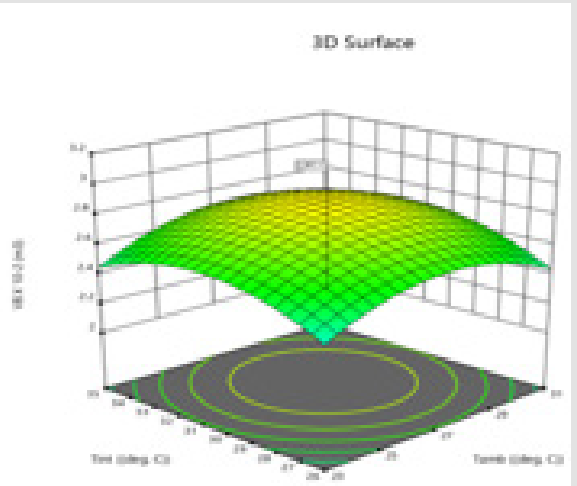

(b)

10 surtace

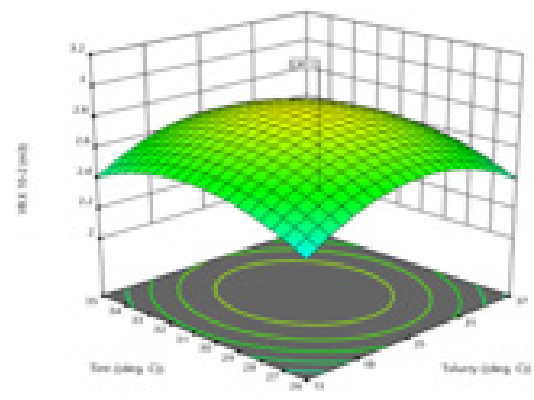

(d)

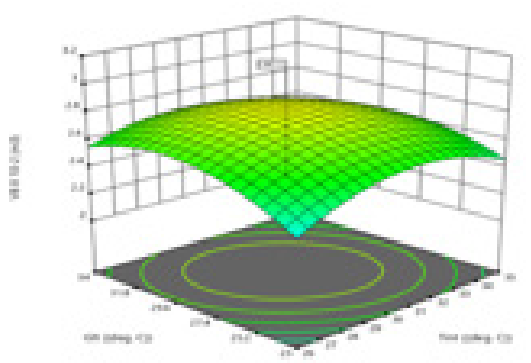

(f)

Figure 1: 3-D plots of the interaction between temperatures on volume of biogas produced of poultry droppings mixed with plantain peels. 
The low values of standard error $(<0.1)$ observed in the intercept and all the model terms showed that the regression model fits the data well, and the prediction was good. The Variance Inflation Factor (VIF) obtained in this study showed that the center points were orthogonal to all other factors in the model. The results showed that there were perfect interactions between the selected variables and the volume of biogas obtained. However, the mutual effects noticed between the slurry temperature with ambient temperature (Figure 1a), and interface temperature with slurry temperature (Figure 1d) indicated the superiority effects over other factors considered for biogas production. The low interactions observed between gas layer temperature with interface temperature (Figure 1f), and interface temperature with ambient temperature (Figure $1 \mathrm{~b}$ ) are far better than that noticed between gas layer temperature with slurry temperature (Figure $1 \mathrm{e}$ ), and gas layer temperature, and ambient temperature (Figure 1c). It was also observed that the highest biogas volume obtained was $3.11 \times 10^{-2} \mathrm{~m}^{3} /$ day at an ambient temperature of $27^{\circ} \mathrm{C}$, the slurry temperature of $25^{\circ} \mathrm{C}$, interface temperature of $30.5^{\circ} \mathrm{C}$, and gas layer temperature of $28.5^{\circ} \mathrm{C}$, respectively. However, statistical analysis by response surface methodology predicted a biogas volume of $3.05 \mathrm{x}$ $10^{-2} \mathrm{~m} 3 /$ day at the same temperatures. It can be concluded that an interface temperature of $27.25^{\circ} \mathrm{C}$ showed a greater effect on biogas production than all other variable temperatures when dealing with the mixture of poultry dropping with plantain peels.

\section{Chemical and Proximate Analysis of the Digestate}

The chemical and proximate analysis of the digestates after the anaerobic digestion shows the percentage variation. Chemical and Proximate analyses were determined using a digital photometer. An effective way of finding the availability of the number of nutrients accessible for bacterial action during digestion is through the determination of the total solids of the wastes. Poultry droppings have a higher potential for organic manure compared with plantain peels because of its higher ash content. However, the high values of nitrogen, phosphorus, and potassium in the digestate indicates that the end product is useful for fertilizer application. The weighted sample of $0.165 \mathrm{~g}$ of the digestate for each of the digester was used in the determination of the proximate analyses results. From the results, it was observed that the digestate gave the value of $\mathrm{pH}, \mathrm{C}, \mathrm{N}$, $\mathrm{C} / \mathrm{N}, \mathrm{P}, \mathrm{K}, \mathrm{Ca}$, and ash content as 7.92, 72.01, 6.23, 4.8:1, 32.41, 4.51, 34.02 and $24 \%$ ash content. The values of NPK from the digestate are $6.23,32.41$, and 4.51 respectively which make it applicable for fertilizer applications and agree with [14].

\section{Conclusion}

Biogas was produced from poultry droppings mixed with plantain peels. The highest biogas volume was $3.11 \times 10^{-2} \mathrm{~m}^{3} /$ day on the $48^{\text {th }}$ day of the fermentation process. The temperatures (interface between slurry and gas, gas layer, ambient, and slurry) measured were within the mesophilic temperature range. The amount of NPK that was measured in the digestate shows that it can be used for fertilizer application. The statistical analysis from RSM used gave the $\mathrm{R}^{2}$ of $99.67 \%$.

\section{References}

1. Nges IA, Escobar F Fu X, Bjornsson L (2011) Benefits of supplementing an industrial waste anaerobic digester with energy crops for increased biogas production. Waste Manag 32(1): 53-59.

2. (2013) Internation Energy Association. Country Reports of Task 37: Energy from Biogas.

3. Sharpley A, Slaton N, Tabler TJ, Van Devender K, Daniels M (2009) Nutrient Analysis of Poultry Litter. Agriculture and Natural Resources FSA9529-PD-6-09N.

4. Suyog V (2010) Biogas Production from Kitchen Waste. Department of Biotechnology and Medical Engineering National Institute of Technology, Rourkela P 8-15.

5. Lantz M, Svensson M, Björnsson L, Börjesson P (2007) The prospects for an expansion of biogas systems in Sweden: Incentives, barriers and potential. Energy policy 35(3): 1830-1843.

6. Peng chong Zhang, Che Jen Lin, James Liu, Pruek Pongprueksa, Simon A Evers and Peter Hart (2014) Biogas production from brown grease using a pilot-scale high-rate anaerobic digester. Renewable energy 68: 304-313.

7. Azadeh Babaee, Jalal Shayegan, Arus Roshani (2013) Anaerobic slurry co-digestion of poultry manure and straws: Effect of organic loading and temperature. Journal of Environmental Health Science and Engineering 11(1): 15 .

8. Budiyono, I Nyoman Widiasa, Seno Johari, S Sunarso (2014) Increasing biogas production rate from cattle manure using rumen fluid as inoculums. International Journal of Science and Engineering 6(1): 3138.

9. Quiroga G, L Castrillon, Y Fernandez Nava, E Maranon, L Negral J (2014) Effect of ultrasound pretreatment in the anaerobic co-digestion of cattle manure with food waste and sludge. Bioresource Technology 154: 7479.

10. Ojolo SJ, Dinrifo RR, Adesuyi KB (2007) Comparative study of Biogas Production from five substrates. Advanced Material Research Journal 18(19): 519-525.

11. Adepoju TF, Olatunbosun BE, Olawale O (2016) Statistical Analysis of Biogas Production from Co-digestion of Cornstalk with Goat Dung using a One Factor Design. Chemistry Research Journal 1(4): 1-10.

12. Nzila C, Wambua P, Githaiga J, Tuigong D, Kiriamiti H, et al. (2008) The potential of a low cost EPAD system in the treatment of textile mill effluents. The Kenya Journal of Mechanical Engineering 4(1).

13. Yadvika A Santosh, Sreekrishnan TR, Kohli S, Rana V (2004) Enhancement of Biogas Production from Solid Substrates using different techniques-a review. Bioresource Technology 95(1): 1-10.

14. KA Adeniran, PO Adepoju, TF Adepoju (2020) Comparative study of biogas production from plantain peels mixed with poultry droppings and poultry droppings only. J Environ Sci Technol ISSN 1994.7887. 
ISSN: 2574-1241

DOI: $10.26717 / B J S T R .2020 .27 .004497$

Adepoju TF. Biomed J Sci \& Tech Res

(C) (i) This work is licensed under Creative BY Commons Attribution 4.0 License

Submission Link: https://biomedres.us/submit-manuscript.php

$\begin{array}{ll}\text { BIOMEDICAL } & \text { Assets of Publishing with us } \\ \text { RESEARCHES } & \text { - Global archiving of articles } \\ \text { - Immediate, unrestricted online access }\end{array}$

